BMJ Surgery, Interventions, $\&$ Health Technologies

\title{
Feasibility of in-office MRI-targeted partial gland cryoablation for prostate cancer: an IDEAL stage 2A study
}

\author{
Spyridon P Basourakos (D) , ${ }^{1}$ Bashir Al Hussein Al Awamlh, ${ }^{1}$ Fernando J Bianco, ${ }^{2}$ \\ Neal A Patel, ${ }^{1}$ Aaron Laviana, ${ }^{3}$ Daniel J Margolis, ${ }^{4}$ Juan M Mosquera, ${ }^{5}$ \\ Timothy D McClure, ${ }^{1}$ Miko Yu, ${ }^{1} \mathrm{Jim} \mathrm{C} \mathrm{Hu}$ (D) ${ }^{1}$
}

To cite: Basourakos SP, Al Hussein Al Awamlh B, Bianco FJ, et al. Feasibility of in-office MRI-targeted partial gland cryoablation for prostate cancer: an IDEAL stage $2 \mathrm{~A}$ study. BMJ Surg Interv Health Technologies 2020;2:e000056. doi:10.1136/ bmjsit-2020-000056

SPB and BAHAA contributed equally.

Received 15 July 2020 Revised 16 September 2020 Accepted 13 October 2020

Check for updates

(C) Author(s) (or their employer(s)) 2020. Re-use permitted under CC BY-NC. No commercial re-use. See rights and permissions. Published by BMJ.

${ }^{1}$ Urology, NewYork-Presbyterian Hospital/Weill Cornell Medical Center, New York, New York, USA ${ }^{2}$ Urology, Urological Research Network, Miami Lakes, Florida, USA

${ }^{3}$ Urology, Vanderbilt University Medical Center, Nashville, Tennessee, USA

${ }^{4}$ Radiology, NewYork-

Presbyterian Hospital/Weill Cornell Medical Center, New York, New York, USA

${ }^{5}$ Pathology, NewYork-

Presbyterian Hospital/Weill

Cornell Medical Center, New York, New York, USA

Correspondence to

Dr Jim C Hu;

Jch9011@med.cornell.edu

\section{ABSTRACT}

Objectives Cryoablation for prostate cancer is typically performed under general anaesthesia. We explore the safety, feasibility and costs of in-office MRI-targeted prostate partial gland cryoablation (PGC) under local anaesthesia. We hypothesise that an office-based procedure under local anaesthesia may yield greater patient convenience and lower health costs with similar outcomes to a general anaesthesia approach.

\section{Design/participants/setting/}

interventions Retrospective study of men diagnosed with clinically significant prostate cancer (grade group $(G G) \geq 2$ ) who elected to undergo in-office PGC under local anaesthesia.

Main outcome measures A total of 55 men with $\mathrm{GG} \geq 2$ prostate cancer underwent $\mathrm{PGC}$ under local anaesthesia, and 35 of 43 men (81.4\%) who attained $\geq 6$ months of follow-up post-treatment underwent MRItargeted surveillance biopsy. We used MRI findings and targeted biopsy to characterise post-PGC oncological outcomes. Complications were categorised using Common Terminology Criteria for Adverse Events (CTCAE). Expanded Prostate Cancer Index-Clinical Practice was used to characterise urinary and sexual function scores at baseline, 4 and 9 months post-PGC. Time-driven activitybased costing was used to determine healthcare costs of in-office PGC.

Results Five (9.1\%) men experienced CTCAE score 3 adverse events. Urinary and sexual function did not change significantly from baseline to 4 months $(p=0.20$ and $p=0.08$, respectively) and 9 months $(p=0.23$ and $p=0.67$, respectively). Twenty-two men (62.9\%) had no cancer or $\mathrm{GG} 1$ and $13(37.1 \%)$ men had $\mathrm{GG} \geq 2$ on post-PGC biopsy. Moreover, the median cost of in-office PGC was US $\$ 4,463.05$ (range US\$4,087.19-US7,238.16) with disposables comprising $69 \%$ of the cost.

Conclusions In-office PGC is feasible under local anaesthesia with favourable functional outcome preservation and adverse events profile at significantly lower costs compared with a general anaesthesia approach.

\section{INTRODUCTION}

The aim of partial gland ablation for prostate cancer is to eliminate cancer while sparing noncancerous prostate tissue to preserve
Key messages

What is already known about this subject?

- Partial gland cryoablation (PGC) is an ablation approach that has been described for prostate cancer focal therapy. It has emerged as an attractive treatment option as it offers minimally invasive cancer treatment with preservation of functional outcomes. Historically, PGC has been performed at ambulatory centres and under general anaesthesia.

\section{What are the new findings?}

- This is the first series of in-office PGC performed under local anaesthesia. We demonstrate that in-office PGC is feasible, well tolerated and has favourable functional outcomes with no significant change in pretreatment versus post-treatment urinary and sexual function. Furthermore, in-office PGC has oncological outcomes comparable to high-intensity focused ultrasound and PGC under general anaesthesia at a significantly lower cost.

How might these results affect future research or surgical practice?

- We demonstrate that in-office PGC is a promising and cost-effective approach with similar outcomes to ablation under general anaesthesia. Our approach may allow urologists to offer an office-based prostate cancer treatment procedure at a better cost and comparable outcomes to procedures under general anaesthesia. Nevertheless, more studies assessing long-term outcomes are needed before widespread dissemination.

urinary, sexual and ejaculatory function. ${ }^{1}$ Interest in prostate gland ablation has grown in the USA due to the recent Food and Drug Administration approval of high-intensity focused ultrasound (HIFU) for prostate tissue ablation and increased use of MRIultrasound fusion targeted (MRI-targeted) prostate biopsy, which improves tumour localisation relative to conventional transrectal ultrasound-guided prostate biopsy. ${ }^{2}$ Various thermal energies such as cryoablation, HIFU, laser ablation and short electric pulses have 
been used for partial gland ablation ${ }^{34}$; however, there is a dearth of comparative outcomes and cost research.

The current post-treatment paradigm of partial gland ablation entails follow-up with active surveillance (prostate specific antigen (PSA), MRI, biopsy). Longitudinal costs of active surveillance have been shown to be more than radical prostatectomy, particularly for younger men with long life expectancy. ${ }^{5}$ Cryoablation has traditionally been a whole prostate gland treatment under general anaesthesia and is less costly compared with HIFU. ${ }^{2}$ The ability to perform an office-based procedure would further attenuate expenses from ambulatory surgery centre and general anaesthesia costs while improving patient convenience. In this pilot study, we present our initial experience with in-office, MRI-targeted partial gland cryoablation (PGC) under local anaesthesia.

\section{MATERIALS AND METHODS}

\section{Study population}

This study included 55 men diagnosed with clinically significant prostate cancer (grade group $(\mathrm{GG}) \geq 2$ ) using targeted biopsy with systematic biopsy at Urological Research Network ( $\mathrm{n}=5$; Florida, USA) and NewYorkPresbyterian/Weill Cornell Medicine ( $n=50$; New York, USA). Men were enrolled in clinical trials for PGC (NCT 02381990 and NCT 03492424 , respectively). Men were counselled that there was a dearth of long-term cancer control outcomes and comparative studies between PGG and whole gland treatment. Additionally, men were counselled regarding conventional treatment options (surveillance, surgery, radiation). All prostate MRIs were reviewed by an experienced uroradiologist (DJM) to plan PGC, using the Prostate Imaging-Reporting and Data System (PI-RADS) V.2 recommendations. Lesions were graded accordingly ${ }^{6}$; none had gross evidence of extraprostatic extension or seminal vesicle invasion. The trial flow is demonstrated in figure 1.

\section{Partial gland cryoablation}

An oral antibiotic (fluroquinolone or trimethoprim/ sulfamethoxazole) was given the morning of PGC and the procedures were conducted in the office setting. Only four men $(7.3 \%)$ asked for a short-acting oral benzodiazepine and none required intravenous access. The perineum was shaved and prepped with betadine in the lithotomy position and a Foley catheter was inserted. The skin, subcutaneous tissue and periprostatic nerves were blocked with $20 \mathrm{~mL}$ of $1 \%$ lidocaine. A biplane ultrasound Noblus probe (Hitachi Aloka, Twinsburg, Ohio, USA) was inserted transrectally. All procedures were performed by two surgeons (JCH and FJB) using the Artemis platform (Eigen, Grass Valley, California, USA). The contoured prostate along with MRI planned ablation zone(s) were

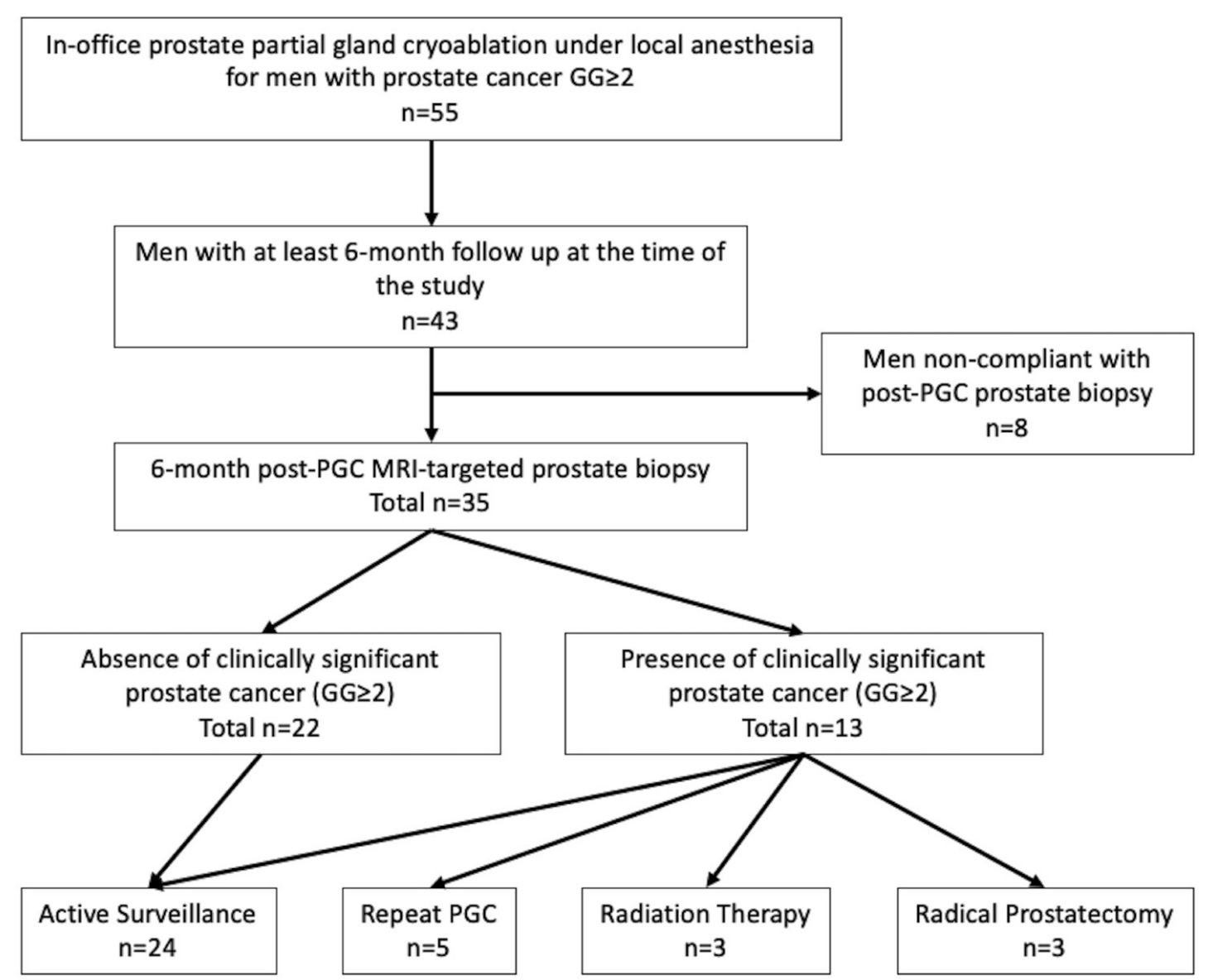

Figure 1 In-office prostate PGC under local anaesthesia trial flow. GG, grade group; PGC, partial gland cryoablation. 
coregistered to ultrasound. A minimum of two cryotherapy probes were transperineally inserted using MRI targeting. The total number of probes used was dependent on the size of the lesion and was at the discretion of the treating surgeon. Men without MRI-visible disease underwent quadrant PGC. Two freeze thaw cycles to negative $40^{\circ} \mathrm{C}$ were performed to ensure tumour lysis ${ }^{7}$; safety of the procedures was enhanced by real-time image fusion monitoring where the ice-ball would cover the target area within the MRI prostate contour. The targeted ablation zone that extended $1.5 \mathrm{~cm}$ beyond the border of the region of interest or reached the boundary of the prostate. ${ }^{8}$ Men were discharged home with an indwelling Foley catheter unless they had low volume tumours without definitive urethral ice-ball impingement.

\section{Follow-up, quality of life and adverse events}

Men followed up for catheter removal within 7 days and PSA 3 months after PGC. Complications were captured by research coordinators uninvolved with clinical care and classified outcomes using the National Cancer Institute Common Terminology Criteria for Adverse Events (CTCAE) V.5.0. ${ }^{9}$ Urinary and sexual function were assessed using the Expanded Prostate Cancer Index for Clinical Practice (EPIC-CP), with lower scores indicating better outcomes, at baseline, at 4 months and 9 months post-PGC ${ }^{10}$ A total of 35 men $(63.6 \%)$ attained 6 -month follow-up. All men underwent post-PGC MRI-targeted and systematic surveillance biopsy at this time. Four men had insurance denial of the MRI and, thus, underwent MRI-targeted biopsy using the pretreatment MRI. Failure of in-office PGC was defined as the detection of clinically significant prostate cancer $(\mathrm{GG} \geq 2)$ on the 6 -month post-PGC biopsy.

\section{Time-driven activity-based costing}

Time-driven activity-based costing (TDABC) is a described strategy to calculate the true cost of healthcare services. ${ }^{11}$ Therefore, it was used to determine the costs of performing in-office, MRI-targeted PGC under local anaesthesia. A process flow map and detailed calculations of every step was performed by one of the authors (AL). Procedure times (the time from Foley catheter insertion to PCG completion) were recorded in the medical record. Personnel, equipment and material costs were all factored in to derive capacity cost rates, which also incorporated indirect costs such as depreciation and employee benefits. These capacity cost rates were then multiplied by the relevant process times, and TDABC was defined as the sum of its resources. We then determined the median cost of in-office PGC for all procedures and compared these costs to PGC under general anaesthesia and HIFU partial gland ablation as previously reported, excluding the follow-up costs. ${ }^{2}$ We compared the cost of in-office PGC under local anaesthesia to PGG under general anaesthesia performed at an ambulatory surgery centre based on resource utilisation, process maps and times for five cases before this series. Furthermore, we compared

\begin{tabular}{ll}
\hline Table 1 Baseline characteristics & \\
\hline Age (years), median (IQR) & $70(63.43-74.96)$ \\
\hline PSA (ng/mL), median (IQR) & $6.6(4.73-9.18)$ \\
\hline MRI findings & \\
\hline Volume (mL), median (IQR) & $39(31.50-54.45)$ \\
\hline Max PI-RADS V.2, n (\%) & \\
3 & $9(17.65)$ \\
4 & $28(54.90)$ \\
5 & $14(27.45)$ \\
Biopsy of target (max GG), n (\%) & \\
2 & $32(58.18)$ \\
3 & $13(23.64)$ \\
4 & $7(12.73)$ \\
5 & $3(5.45)$ \\
\hline
\end{tabular}

Prostate volume was obtained from prostate MRI.

GG, grade group; PI-RADS V.2, Prostate Imaging-Reporting and Data System V.2; PSA, prostate specific antigen.

the in-office PGC to HIFU, because the latter is currently an alternative modality for partial gland ablation in the USA. $^{2} 11$

\section{RESULTS}

\section{Patient characteristics}

Median age was 70 years (IQR 63.4-75), median pretreatment PSA was $6.6 \mathrm{ng} / \mathrm{mL}$ (IQR 7.7-9.2) and median prostate volume was $39 \mathrm{cc}$ (IQR 31.5-54.5) (table 1, figure 2). Forty-two men $(83 \%)$ had PI-RADS category $\geq 4$ lesions. Thirty-two (58.2\%) men had GG 2, $13(23.6 \%)$ had GG 3, $7(12.7 \%)$ had GG 4 and three $(5.5 \%)$ had GG 5 on pretreatment biopsy (table 1, figure 2). Two cryoablation probes were used in $38(69 \%)$ men, three probes in $7(12 \%)$ men and 4-6 probes were used for the other subjects. Four men were discharged from clinic without an indwelling catheter because the treatment area was deemed small and away from the urethra.

\section{Post-treatment outcomes}

We observed a $65 \%$ median PSA decline, although a quarter of patients had greater than a $94 \%$ decrease. The median duration of urethral catheterisation was 6 days (IQR 3-7). The prostate volume decreased by $18.3 \%$ on post-treatment MRI. On post-PGC MRI, almost half of men $(n=15,48.4 \%)$ did not have an identifiable lesion and nine men (29.1\%) had PI-RADS 4 or 5 lesion. Twenty-two men had a benign $(42.9 \%)$ or GG1 $(20.0 \%)$ on post-PGC biopsy, whereas, 11 (31.4\%) had GG2, 1 (2.9\%) had GG3 and another (2.9\%) had GG4 (table 2, figure 2). Out of the 13 (37\%) men that had recurrence (GG $\geq 2), 7$ $(54 \%)$ were found to have in-field while $6(46 \%)$ had outof-field recurrences (figure $3 \mathrm{~A}$ ).

Twenty-four (68.6\%) men were opted for active surveillance after PGC (two with GG2 and seven with GG1). 
A

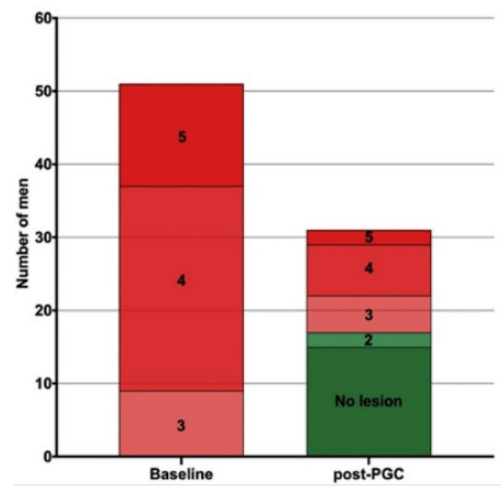

B

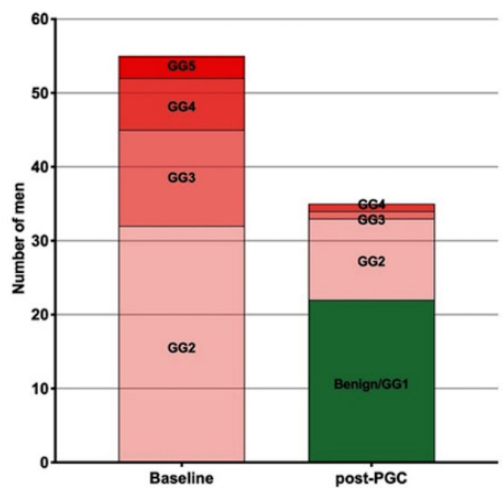

Figure 2 Changes in radiographical and pathological features between baseline and post-PGC. Bar graphs showing changes in PI-RADS category (A) and grade group (B) and box and whisker plots showing changes in PSA (C) between baseline and post-PGC. GG, grade group; PGC, partial gland cryoablation; PI-RADS, Prostate Imaging-Reporting and Data System.

The rest of the men with GG2 or above on surveillance biopsy underwent repeat PGC $(n=5)$, radical prostatectomy $(n=3)$ or radiation therapy $(n=3)$ (figure $3 B)$. The men who underwent salvage radical prostatectomy had

\begin{tabular}{|c|c|}
\hline Catheter duration (days), median (IQR) & $6(3-7)$ \\
\hline PSA decrease from baseline $(\mathrm{ng} / \mathrm{ml})$, median (IQR) & $4.3(2-6.2)$ \\
\hline \multicolumn{2}{|l|}{ MRI findings } \\
\hline $\begin{array}{l}\% \text { decrease in prostate volume from baseline, } \\
\text { median (IQR) }\end{array}$ & $18.3(0-28.0)$ \\
\hline \multicolumn{2}{|l|}{ Max PI-RADS V.2, n (\%) } \\
\hline No lesions/not identified & $15(48.40)$ \\
\hline 2 & $2(6.45)$ \\
\hline 3 & $5(16.13)$ \\
\hline 4 & $7(22.57)$ \\
\hline 5 & $2(6.45)$ \\
\hline \multicolumn{2}{|l|}{ Post-treatment targeted biopsy (max GG), n (\%) } \\
\hline Benign & $15(42.86)$ \\
\hline 1 & $7(20.0)$ \\
\hline 2 & $11(31.43)$ \\
\hline 3 & $1(2.86)$ \\
\hline 4 & $1(2.86)$ \\
\hline \multicolumn{2}{|l|}{ Recurrence, n (\%) } \\
\hline In-field & $7(20.00)$ \\
\hline Out-of-field & $6(17.14)$ \\
\hline Ablated site & $10(28.57)$ \\
\hline Non-ablated site & $3(8.57)$ \\
\hline \multicolumn{2}{|l|}{ Post-treatment plan, n (\%) } \\
\hline Active surveillance & $24(68.57)$ \\
\hline Repeat PGC & $5(14.29)$ \\
\hline Radical prostatectomy & $3(8.57)$ \\
\hline Radiation treatment & $3(8.57)$ \\
\hline
\end{tabular}

GG, grade group; PGC, prostate gland cryoablation; PI-RADS V.2, Prostate Imaging-Reporting and Data System V.2; PSA, prostate specific antigen. no postoperative complications. Two men had GG2 on both biopsy and prostatectomy specimens while the other man was downgraded from GG4 on biopsy to GG3 at prostatectomy.

There were no significant changes in mean EPIC-CP urinary and sexual function scores from baseline to 4 months $(0.71$ vs $1.17, \mathrm{p}=0.20$ and 3.41 vs $4.84, \mathrm{p}=0.08$, respectively) and from baseline to 9 months ( 0.71 vs 1.21 , $\mathrm{p}=0.23$ and 3.41 vs $3.83 \mathrm{p}=0.67$, respectively) post-PGC (table 3). No man experienced urinary incontinence.

All men completed the procedure successfully. Thirteen men (24\%) experienced an adverse event (table 4). In total, there were $22(40 \%)$ CTCAE V.5 score 2 and 5 $(9.1 \%)$ score 3 events within the first 30 days, although no reported sequelae occurred beyond this interim. There were no severe adverse events (CTCAE grade $>3$ ).

\section{Total costs}

TDABC assessment demonstrated the median cost of in-office PGC under local anaesthesia was US $\$ 4,463.05$ (range US\$4,087.19-US\$7,238.16) with the majority of costs consisting of cryotherapy disposables (US\$3,086.45). Overhead, depreciation and the remaining fixed indirect costs of the procedure, Artemis device and MRI itself remained a substantial cost driver, totalling US $\$ 1,376.61$. In-office PGC has an approximately sixfold lower fixed cost compared with PGC under general anaesthesia, which contributes to an overall lower cost. Moreover, HIFU under general anaesthesia was almost twice as costly at US\$8,449.11 compared with in-office PGC. The higher costs of ASC PGC and HIFU are fueled by the need to be done under general anaesthesia and longer operative times (median length of procedure for in-office PGC 28 (range 16-58 min) minutes vs $120 \mathrm{~min}$ (range 90-150 min) for ASC PGC and HIFU) (table 5).

\section{DISCUSSION}

Advances in prostate MRI and targeted biopsy has piqued interest in prostate gland partial ablation. ${ }^{12}$ Additionally, partial gland ablation offers the potential to avoid adverse 
A

Post Treatment Targeted Biopsy

- Benign or GG1 = GG2, GG3, GG4 = In-field recurrence = Out-of-field recurrence

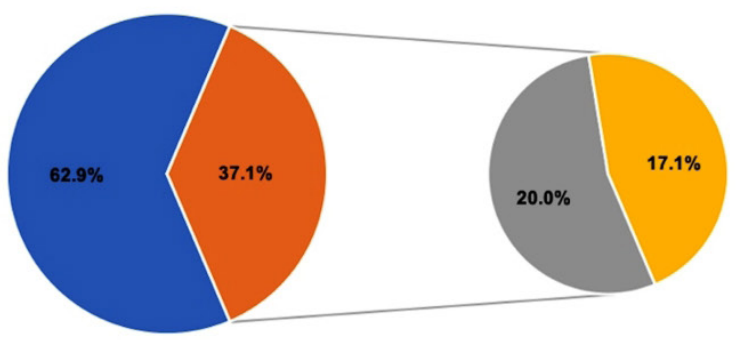

B Post Treatment Plan

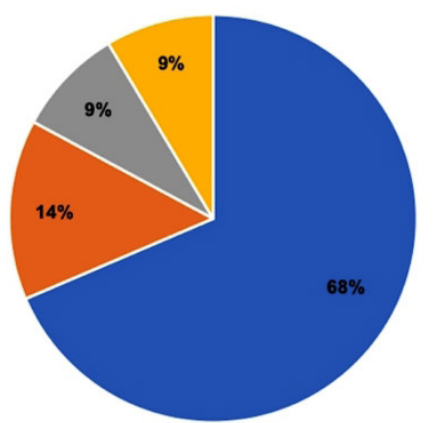

- Active surveillance

- Repeat prostate gland ablation

- Radical prostatectomy

Radiation therapy

Figure 3 Oncological outcomes and treatment plans following prostate PGC for 35 men. (A) Post-treatment targeted biopsy results. (B) Treatment plan after prostate PGC. GG, grade group; PGC, partial gland cryoablation.

effects associated with traditional whole-organ therapy, such as urinary incontinence and sexual dysfunction. ${ }^{12}$ As men are willing to make trade-offs between side effects of treatment and cancer control, prostate gland ablation may preserve health related quality of life and delay definitive therapy. ${ }^{13}$ However, the Idea, Development, Exploration, Assessment and Long-term study (IDEAL) categorises partial gland ablation at development stage 2A for surgical innovation because comparative outcome evidence is lacking. ${ }^{14}$

Our pilot IDEAL stage 2A study has several important findings. It is the first to demonstrate that in-office PGC under local anaesthesia is feasible, reproducible and well tolerated. Natarajan et al described the performance of focal laser ablation in a clinic setting under local anaesthesia; however, all subjects had intravenous access for pain medications and sedation administration. ${ }^{4}$ In the current series, none of the subjects required intravenous sedation and only four (7.3\%) needed an oral benzodiazepine for the procedure. Furthermore, there may inherent advantages in performing cryoablation versus, other energy modalities under general anaesthesia. For instance, once the cryoablation probe is activated and 'stuck', it remains fixed in place refractory to moderate movement; whereas other energies require complete absence of movement. ${ }^{115}$

Second, we found favourable functional outcomes with no significant change in pretreatment versus posttreatment urinary and sexual function. This is consistent with a multicentre prospective study of 122 men from the UK, who underwent focal cryotherapy for intermediaterisk to high-risk prostate cancer. Similarly, none of the men had urinary incontinence at 3 years, although $16 \%$ experienced erectile dysfunction. ${ }^{16}$ Moreover, our in-office approach for PGC was safe and adverse event evaluation showed 22 CTCAE V.5 score 2 and only five CTCAE V.5 score 3 complications in 55 men. The most common CTCAE V.5 score 2 adverse events were urinary retention and urinary tract infections that were treated with urethral catheter drainage and oral antibiotics, respectively. These adverse events compare favourably to other series. For instance, 6 out of 10 men had a CTCAE V.5 score 2 adverse events after focal laser ablation therapy under local anaesthesia. ${ }^{4}$ Bass et al reported ClavienDindo grade I in 35 (23\%) men, grade II in 12 (8\%) men and grade III in four (2.6\%) out of 153 men that underwent HIFU for localised prostate cancer. Similarly to our series, urinary retention was the most common adverse

\begin{tabular}{|c|c|c|c|c|}
\hline EPIC-CP, n (\%) & Baseline & 4 months post-PGC & 9 months post-PGC & $P$ value \\
\hline \multicolumn{5}{|l|}{ Overall urinary function } \\
\hline No problem & $22(52.38)$ & $19(57.58)$ & $13(59.09)$ & \\
\hline Very small problem & $4(9.52)$ & $8(24.24)$ & $2(9.09)$ & \\
\hline Small problem & $8(40)$ & $4(12.12)$ & $6(27.27)$ & \\
\hline Moderate problem & $6(14.29)$ & $1(3.03)$ & $1(4.55)$ & \\
\hline Big problem & $2(4.76)$ & $1(3.03)$ & $0(0.00)$ & \\
\hline Incontinence symptom score, mean (SD) & $0.71(1.37)$ & $1.17(1.56)$ & $1.21(1.72)$ & $0.20 / 0.23^{\star}$ \\
\hline Sexual function score, mean (SD) & $3.41(3.32)$ & $4.84(3.55)$ & $3.83(3.76)$ & $0.08 / 0.67^{\star}$ \\
\hline
\end{tabular}

*Baseline vs 4 months PGC and 9 months PGC, respectively.

EPIC-CP, Expanded Prostate Cancer Index-Clinical Practice; PGC, partial gland cryoablation. 
Table 4 Adverse events reported at 30 days after prostate partial gland cryoablation

\begin{tabular}{lll}
\hline Complication & $\begin{array}{l}\text { CTCAE } \\
\text { V.5 score }\end{array}$ & $\begin{array}{l}\text { Number of men } \\
\text { with adverse } \\
\text { events }\end{array}$ \\
\hline $\begin{array}{l}\text { Bladder spasm, } \\
\text { antispasmodics indicated }\end{array}$ & 2 & 1 \\
$\begin{array}{l}\text { Erectile dysfunction, } \\
\text { intervention indicated }\end{array}$ & 2 & 4 \\
$\begin{array}{l}\text { Hematuria, irrigation } \\
\text { indicated }\end{array}$ & 2 & 1 \\
$\begin{array}{l}\text { Urinary frequency, medical } \\
\text { management indicated }\end{array}$ & 2 & 2 \\
$\begin{array}{l}\text { Urinary retention, } \\
\text { recatheterisation indicated }\end{array}$ & 2 & 9 \\
$\begin{array}{l}\text { UTI, oral intervention } \\
\text { indicated }\end{array}$ & 2 & 5 \\
$\begin{array}{l}\text { UTI, IV intervention } \\
\text { indicated } \\
\begin{array}{l}\text { UTI, IV and invasive } \\
\text { intervention indicated }\end{array}\end{array}$ & 3 & 2 \\
$\begin{array}{l}\text { Erectile dysfunction, } \\
\text { intervention not helpful }\end{array}$ & 3 & 1 \\
\hline
\end{tabular}

CTCAEV.5, National Cancer Institute Common Terminology Criteria for Adverse Events V.5; IV, intravenous; UTI, urinary tract infection.

event (20 men, 13.1\%). ${ }^{17}$ In contrast to HIFU and focal laser ablation, PGC may be monitored with real-time ultrasonography, with $0^{\circ} \mathrm{C}$ temperatures at the leading edge of the ice-ball. ${ }^{7}$

The short-term oncological outcomes of in-office PGC were comparable to other partial gland ablation modalities under general anaesthesia. In our series, the recurrence rate was $37 \%$ at 6 months. Similarly, Mortezavi et al report a $41 \%$ detection rate of clinically significant prostate cancer on 6-month biopsy after HIFU. ${ }^{18}$ Likewise, Natarajan et al recently reported an in-office, transrectal focal laser ablation experience using Artemis guidance, and described an in-field recurrence rate of $40 \%$ with GG
2 or 3 on follow-up 6-month biopsy. ${ }^{4}$ The difference in in-field recurrence rates between Natarajan et al and our study may be due to the lower radius of laser ablation as compared with cryoablation. Furthermore, all 10 participants in the Natarajan et al study had higher GG disease (GG $\geq 3$ ) compared with our study, where only 23 out of 55 patients $(41.8 \%)$ had $G G \geq 3$. This may also help explain our lower recurrence rates.

We observed that definitive treatment after PGC was feasible and safe. None of the three men who underwent salvage radical prostatectomy experienced complications. All three men required $0-1$ pads (EPIC-CP score 0-1) and had erections sufficient for intercourse at 4-month follow-up (EPIC-CP score 0-1). Consistent with our results, a recent systematic review on treatment options after failure of focal therapy showed promising oncological outcomes, and urinary and sexual function outcomes that are not markedly different from those associated with primary treatment. ${ }^{19}$

Finally, with greater emphasis on value-based care nationally, with value defined as outcomes/costs, we examined resource utilisation and costs of this versus other partial gland ablation approaches. Therefore, we performed TDABC analysis to evaluate in-office PGG under local anaesthesia. We demonstrated that the cost of in-office PGC is almost $50 \%$ and $75 \%$ of the costs of HIFU and PGC at an ambulatory surgery centre, respectively. The major cost driver of PGC was disposables that comprised more than two-thirds of the total cost. Nevertheless, by eliminating the need for general anaesthesia and/or sedation, we demonstrated that in-office PGC is a cost-effective alternative to ASC PGC and HIFU. In the absence of demonstrating superior outcomes for competing partial gland ablation technologies, the lowest cost approach offers the best value.

Our study must be interpreted in the context of the study design. First, this is a non-comparative study and long-term outcomes are needed to assess cancer control. Because this is an IDEAL 2A study, our focus is on safety and feasibility. Additional follow-up is needed to attain long-term oncological outcomes for in-office PGC. However, our study is noteworthy, as it illustrates that

Table 5 Comparison of time-driven activity-based costing between in-office prostate PGC, ambulatory surgery centre PGC and HIFU prostate gland ablation

\begin{tabular}{llll}
\hline & In-office PGC & ASC PGC & HIFU \\
\hline Disposable costs & US $\$ 3,086.44$ & US $\$ 3,086.44$ & US $\$ 2,400.00^{\star}$ \\
& $(2,753.71-5,753.71)$ & $(2,753.71-5,753.71)$ & US $\$ 6,049.11$ \\
Fixed costs & US\$305.73 & US $\$ 1,859.31$ & $(4,912.79-7,185.43)$ \\
MRI-targeting biopsy platform cost & $(262.60-413.57)$ & $(1,404.78-2,995.63)$ & N/A \\
Total costs & US\$1,070.88 & US\$1,070.88 & US\$8,449.11 \\
& $(4,087.19-7,238.16)$ & US\$6,016.63 & $(7,312.79-9,585.43)$ \\
\hline
\end{tabular}

Median (range) in dollars.

*Disposable cost is fixed

ASC, ambulatory surgery centre; ;HIFU, high-intensity focused ultrasound; N/A, not available; PGC, partial gland cryoablation. 
an office-based treatment paradigm for prostate cancer is feasible, particularly in light of greater emphasis on value-based care. ${ }^{2}$ Second, we used PI-RADS to assess our subjects post-PGC surveillance MRI, despite the fact that PI-RADS was not conceived for post-treatment MRI evaluation. There is currently no framework in place to enable standardised reporting and interpretation of post-PGC surveillance MRI. ${ }^{20}$ Our recurrence rates are consistent with similar studies. Third, the ability to differentiate between in and out of field recurrences is limited by prostate volume reduction that cannot be clearly delineated with post-treatment MRI. ${ }^{21}$ Finally, although the TDABC analysis demonstrates the cost-effectiveness of in-office PGC, we did not model costs of complications related to PGC.

In summary, in-office PGC is a promising approach with similar outcomes to ablation under general anaesthesia. However, adherence to biopsy surveillance is critical, as the proper follow-up beyond a clinical trial mandated end of study biopsy is still uncertain. ${ }^{21}$

\section{CONCLUSIONS}

We demonstrate that in-office PGC under local anaesthesia is technically feasible and safe for men with localised prostate cancer. In-office PGC demonstrated comparable short-term oncological control and functional outcomes versus HIFU and PGC series performed under general anaesthesia. Despite favourable short-term outcomes, more studies assessing long-term biopsy results are needed before widespread dissemination.

\section{Twitter Spyridon P Basourakos @sbasourakos and Jim C Hu @jimhumd}

Funding JCH receives research support from the Frederick $\mathrm{J}$ and Theresa Dow Wallace Fund of the New York Community Trust. FJB has published a patent application entitled: System and Method for Prostate Treatment under Local Anesthesia. USA 20200108222 A1. PCT /USIS/24404 -Filed 03/25/2017. Pub 9 April 2020.

\section{Competing interests None declared.}

Patient consent for publication Not required.

Ethics approval The Institutional Review Boards of Urological Research Network (FL, USA) and NewYork-Presbyterian/Weill Cornell Medicine (NY, USA) approved this study (13-1010 and 1702018011, respectively).

Provenance and peer review Not commissioned; externally peer reviewed.

Data availability statement Data are available on reasonable request.

Open access This is an open access article distributed in accordance with the Creative Commons Attribution Non Commercial (CC BY-NC 4.0) license, which permits others to distribute, remix, adapt, build upon this work non-commercially, and license their derivative works on different terms, provided the original work is properly cited, appropriate credit is given, any changes made indicated, and the use is non-commercial. See: http://creativecommons.org/licenses/by-nc/4.0/.

\section{ORCID iDs}

Spyridon P Basourakos http://orcid.org/0000-0002-7458-4593

Jim C Hu http://orcid.org/0000-0003-2562-8024

\section{REFERENCES}

1 Valerio M, Cerantola Y, Eggener SE, et al. New and established technology in focal ablation of the prostate: a systematic review. Eur Urol 2017;71:17-34.

2 Hu JC, Laviana A, Sedrakyan A. High-Intensity focused ultrasound for prostate cancer: novelty or innovation? JAMA 2016;315:2659-60.

3 Murray KS, Ehdaie B, Musser J, et al. Pilot study to assess safety and clinical outcomes of irreversible electroporation for partial gland ablation in men with prostate cancer. J Urol 2016;196:883-90.

4 Natarajan S, Jones TA, Priester AM, et al. Focal laser ablation of prostate cancer: feasibility of magnetic resonance ImagingUltrasound fusion for guidance. J Urol 2017;198:839-47.

5 Lao C, Edlin R, Rouse P, et al. The cost-effectiveness of active surveillance compared to watchful waiting and radical prostatectomy for low risk localised prostate cancer. BMC Cancer 2017;17:529.

6 Weinreb JC, Barentsz JO, Choyke PL, et al. PI-RADS Prostate Imaging - Reporting and Data System: 2015, Version 2. Eur Urol 2016;69:16-40.

7 Bischof JC, Smith D, Pazhayannur PV, et al. Cryosurgery of Dunning AT-1 rat prostate tumor: thermal, biophysical, and viability response at the cellular and tissue level. Cryobiology 1997;34:42-69.

8 Priester A, Natarajan S, Khoshnoodi P, et al. Magnetic resonance imaging underestimation of prostate cancer geometry: use of patient specific molds to correlate images with whole Mount pathology. $J$ Urol 2017;197:320-6.

9 CTCAE. Common terminology criteria for adverse events. Available: https://ctep.cancer.gov/protocoldevelopment/electronic_ applications/docs/CTCAE_v5_Quick_Reference_8.5x11.pdf

10 Wei JT, Dunn RL, Litwin MS, et al. Development and validation of the expanded prostate cancer index composite (EPIC) for comprehensive assessment of health-related quality of life in men with prostate cancer. Urology 2000;56:899-905.

11 Laviana AA, Ilg AM, Veruttipong D, et al. Utilizing time-driven activitybased costing to understand the short- and long-term costs of treating localized, low-risk prostate cancer. Cancer 2016;122:447-55.

12 Ward JF, Jones JS. Focal cryotherapy for localized prostate cancer: a report from the National cryo on-line database (cold) registry. BJU Int 2012;109:1648-54

13 NCRI. Evaluating the trade-offs men with localised prostate cancer make between the risks and benefits of treatments: the compare study | NCRI cancer conference Abstracts. secondary evaluating the trade-offs men with localised prostate cancer make between the risks and benefits of treatments: the compare study | NCRI cancer conference Abstracts. Available: http://abstracts.ncri.org.uk/abstract/ evaluating-the-trade-offs-men-with-localised-prostate-cancer-makebetween-the-risks-and-benefits-of-treatments-the-compare-study/ [Accessed 4 Dec 2018].

14 McCulloch P, Altman DG, Campbell WB, et al. No surgical innovation without evaluation: the ideal recommendations. Lancet 2009;374:1105-12.

15 Pfeiffer D, Berger J, Gross A. Single application of high-intensity focused ultrasound as primary therapy of localized prostate cancer: treatment-related predictors of biochemical outcomes. Asian J Urol 2015;2:46-52.

16 Shah TT, Peters M, Eldred-Evans D, et al. Early-Medium-Term outcomes of primary focal cryotherapy to treat nonmetastatic clinically significant prostate cancer from a prospective multicentre registry. Eur Urol 2019;76:98-105.

17 Bass R, Fleshner N, Finelli A, et al. Oncologic and functional outcomes of partial gland ablation with high intensity focused ultrasound for localized prostate cancer. J Urol 2019;201:113-9.

18 Mortezavi A, Krauter J, Gu A, et al. Extensive histological sampling following focal therapy of clinically significant prostate cancer with high intensity focused ultrasound. J Urol 2019;202:717-24.

19 Marra G, Valerio M, Emberton M, et al. Salvage local treatments after focal therapy for prostate cancer. Eur Urol Oncol 2019;2:526-38.

20 Al Hussein Al Awamlh B, Margolis DJ, Gross MD, et al. Prostate multiparametric magnetic resonance imaging features following partial gland cryoablation. Urology 2020;138:98-105.

21 Valerio M, Ahmed HU, Emberton M, et al. The role of focal therapy in the management of localised prostate cancer: a systematic review. Eur Urol 2014;66:732-51. 